\title{
O processo diagnóstico do HIV no contexto de relacionamento estáveis: Interpretação descritiva
}

\author{
Ana Paula Vieira de Deus ${ }^{1}$ e Vanessa da Silva Carvalho Vila ${ }^{1}$
}

\begin{abstract}
${ }^{1}$ Escola de Ciências Sociais e da Saúde, Pontifícia Universidade Católica de Goiás, Brasil anapaulavdeus@gmail.com; vscvila@uol.com.br | https://orcid.org/0000-0002-4770-9688; https://orcid.org/0000-0002-1785-8682
\end{abstract}

Resumo: Introdução: O crescente aumento de infecções pelo HIV entre pessoas que vivenciam relacionamentos estáveis, indica a dificuldade da prevenção no contexto dos relacionamentos estáveis. Objetivo: Compreender o processo diagnóstico do HIV no contexto de relacionamentos estáveis. Método: Estudo descritivo interpretativo com 17 pessoas soropositivas para o HIV e três parcerias (duas soronegativas e uma soropositiva). Essas pessoas foram atendidas em um serviço de saúde ambulatorial da região Centro-Oeste do Brasil. Foi conduzida análise temática interpretativa. Resultado: O processo diagnóstico do HIV foi marcado por fatores determinantes para a busca do serviço de saúde, após a vivência de sintomas, exames de rotina e a confirmação da contaminação pela parceria. Os participantes atribuíram as possíveis causas de contaminação pelo vírus, às relações sexuais desprotegidas, ao compartilhamento de materiais e acidente com material biológico. Receber o diagnóstico foi descrito como um caminho solitário, marcado por sentimentos de negação, sofrimento e isolamento que trouxe para a vida dessas pessoas demandas terapêuticas e sociais complexas, sendo necessário a readaptação às atividades de vida diária. Verificou-se que o uso do preservativo, antes do diagnóstico do HIV era um desafio. Muitos não usavam por confiar na parceria estável. Conclusão: A descoberta do HIV trouxe consigo mudanças e adaptações necessárias para manutenção da vida. O preconceito, o medo do julgamento e o estigma sãos os principais desafios na vivência do HIV, sendo de grande responsabilidade dos serviços.

Palavras-chave: HIV; Síndrome de Imunodeficiência Adquirida; Cônjuges; Relações Interpessoais; Pesquisa Qualitativa.

\section{The HIV Diagnostic Process in the Context of Stable Relationships: Interpretive Description}

\begin{abstract}
Introduction: The lack of strategies for HIV prevention, aimed at couples, brought to light a distinct vulnerability, as they do not feel they belong to a population exposed to the infection, providing the opportunity for a late diagnosis. Objective: To understand the experience of HIV with an emphasis on facing the diagnostic process in the context of stable relationships. Interpretive thematic analysis was implemented. Method: This is a descriptive, interpretive study. Twenty people participated, 17 of whom were HIV positive and three partnerships (two HIV negative and one HIV positive). These people were treated at an outpatient health service specialized in the care of people with HIV / AIDS in the Midwest region of Brazil Result: The HIV diagnostic process was marked by determining factors for the search for the health service, after the experience symptoms, routine exams and confirmation of contamination by the partnership. Participants attributed the possible causes of contamination by the virus, unprotected sex, sharing of materials and accidents with biological material. Receiving the diagnosis was described as a lonely path, marked by feelings of denial, suffering, and isolation that brought complex therapeutic and social demands to these people's lives, requiring readaptation to activities of daily living. It was found that condom use before HIV diagnosis was a challenge. Many did not use it because they trusted the stable partnership. Conclusion: The discovery of HIV brought changes and adaptations necessary to maintain life. Prejudice, fear of judgment and stigma are the main challenges in the experience of HIV, with great responsibility for the services.
\end{abstract}

Keywords: HIV; Acquired Immunodeficiency Syndrome; Spouses; Interpersonal Relations; Qualitative research.

\section{Introdução}

A infecção pelo HIV, considerada problema de saúde pública, atinge principalmente as populações vulneráveis, em especial, os países em desenvolvimento, como o Brasil. A cada ano há aproximadamente 2,1 milhões de casos novos de infecção e aproximadamente $25 \%$ das pessoas infectadas não tem conhecimento do seu diagnóstico, (Granich et al., 2017; Mogobe et al., 2016). 
Apesar dos avanços em termos da disponibilidade de terapias medicamentosas e preventivas, observa-se que o comportamento do paciente distanciado da rede de atenção à saúde, a percepção negativa da enfermidade, e um contexto de vulnerabilidade sexual, dificultam a vinculação deste usuário aos serviços de saúde. Somado a isso, observa-se a dificuldade para o gerenciamento do risco entre pessoas que vivenciam relacionamentos estáveis e estão expostas ao risco de abandonar os métodos preventivos ao longo do tempo (Paiva et al., 2008; Teixeira et al., 2006).

Investigar a vivência do HIV no contexto de parcerias estáveis considerando aspectos sociais, culturais e terapêuticos é fundamental para que profissionais de saúde e gestores municipais, estaduais e federais conheçam a perspectiva e as necessidades de aprendizagem desses indivíduos(Maksud, 2009).

O presente estudo foi desenvolvido com objetivo de compreender o processo diagnóstico do HIV no contexto de relacionamentos estáveis. Os resultados trazem a experiência de pessoas soropositivas e suas parcerias estáveis e fornecem evidências científicas importantes para o planejamento de ações em saúde e reforça a importância do suporte informacional para promoção da saúde desses casais.

\section{Metodologia}

Estudo descritivo interpretativo que utilizou abordagem analítica e construtivista com o intuito de criar formas para facilitar a compreensão de fenômenos clínicos e vivências na prática clínica, a fim de responder a questionamentos complexos e relevantes, por meio do conhecimento teórico e prático(Thorne, 2016). A descrição interpretativa reconhece que ambos, o indivíduo e a realidade social construída, estão intersubjetivamente relacionados e compartilham significados equivalentes em termos da experiência da saúde e da enfermidade(Thorne, 2016).

O estudo foi desenvolvido em um serviço de saúde ambulatorial especializado no atendimento de pessoas com HIV/AIDS, da região Centro-Oeste do Brasil. Os critérios de inclusão foram: ter idade superior a 18 anos; ter diagnóstico de HIV há mais de seis meses; fazer tratamento no serviço especializado; ter relacionamento afetivo sexual estável.

Considerou-se estável, o relacionamento autodeclarado pelo participante, independente do tempo de união, podendo ser namorados, noivos, casados. Também foi considerado elegível, caso o participante soropositivo autorizasse, o parceiro que atendesse aos seguintes critérios de inclusão: ter idade superior a 18 anos; saber o diagnóstico do companheiro, residir na região metropolitana de Goiânia.

Foram excluídas pessoas que apresentassem registro no prontuário de distúrbios da fala e/ou auditivo severo sem uso de tecnologia assistiva, com isso impedidos de compreender as questões da entrevista.

A coleta de dados ocorreu de abril a agosto de 2019. Optou-se por identificar os potenciais participantes por meio da verificação diária da lista de atendimentos no ambulatório para consulta com os médicos especialistas, mediante abordagem inicial para identificar a situação de parceira estável.

Antes de iniciar as entrevistas, foi realizado o processo de consentimento informado. Após a leitura do termo de consentimento livre e esclarecido (TCLE), todos que consentiram assinaram o documento. Considerando o critério de saturação teórica, por meio da avaliação processual (coleta e análise simultâneas) da consistência e força suficiente das informações para o rigor da descrição interpretativa(Malterud et al., 2016).

Todas as entrevistas foram realizadas individualmente, em uma sala privativa no serviço de saúde, manteve-se também o sigilo e anonimato dos participantes. Os casais foram entrevistados separadamente, para não haver possibilidade de interferência nas respostas informadas, e para que ambos tivessem mais tranquilidade e não se sentissem intimidados com a presença do parceiro. 
As entrevistas semiestruturadas foram norteadas por roteiros específicos contemplando informações sociodemográficas, clínicas e as questões norteadoras explorando: como as pessoas soropositivas para o HIV e parcerias estáveis descrevem a trajetória vivenciada para o diagnóstico de HIV? Como ocorreu o enfrentamento deste diagnóstico no contexto de vida social, sexual e afetiva?

As entrevistas tiveram duração de 15 a 62 minutos, com média de 32 minutos. Todo material gravado foi transcrito na íntegra e submetido à análise temática interpretativa por meio de seis etapas: familiarização com os dados, identificação dos códigos, agrupamento dos códigos em núcleos temáticos, revisão dos núcleos temáticos, definição e nomeação final dos núcleos temáticos, elaboração da descrição e interpretação dos significados expressos pelos participantes em cada núcleo(Braun \& Clarke, 2014).

Durante a análise interpretativa, cada transcrição foi lida em profundidade, e as descrições foram feitas com base nas transcrições, codificações e agrupamento dos códigos em núcleos temáticos que possibilitaram as interpretações e inferências relacionadas à vivência do HIV no contexto dos relacionamentos estáveis. Este processo indutivo foi implementado por meio de técnicas de análise constante comparativa, abordagens iterativas e recíprocas para organização e análise dos dados. Os critérios para a confiabilidade da análise foram: (1) gravação digital dos relatos e transcrições na integra checado pelas pesquisadoras; (2) conferência dos códigos e núcleos temáticos ao longo de todo o processo de análise dos dados.

O estudo foi aprovado pelo Comitê de Ética em Pesquisa e obedeceu as normativas brasileiras para condução de pesquisas envolvendo seres humanos (Guerriero, 2016). Todos/as os/as participantes assinaram o Termo de Consentimento Livre e Esclarecido.

\section{Resultados}

Participaram do estudo 20 pessoas que vivenciam relacionamentos estáveis. Entre essas, 17 são pacientes HIV positivo em acompanhamento no serviço de saúde, uma parceria soropositiva e duas parcerias soronegativas. O tempo de diagnóstico de HIV positivo foi de nove meses a quatro anos. Entre os participantes HIV positivo, 11 são do sexo masculino e seis do sexo feminino, com mediana de idade de 38 anos (IQ: 32 - 43 anos). A maioria dos participantes se identificaram como heterossexuais. $O$ tempo de relacionamento entre os casais foi de três meses a 24 anos. Nove participantes vivenciam relacionamentos estáveis soroconcordantes; seis participantes HIV positivos vivenciam relacionamento sorodiscordante.

A maioria dos participantes mencionaram transmissão sexual e a vivência prévia de sintomas relacionados ao HIV e de situações e comportamentos de risco, tais como relacionamentos conflituosos (traição) e vulnerabilidade (sexo sem proteção).

A percepção de não estarem inseridos em "grupos de risco", interferiu no processo diagnóstico, principalmente para a realização dos exames de rotina. Alguns mencionaram que não tinham a percepção da possibilidade desta enfermidade e descreveram que o HIV, até então, era considerado "doença do outro".

[...] eu jamais imaginei [...] nunca na vida! [...] O problema é que a gente acha que nunca vai acontecer com a gente e " acha que não existe" e é aí que você acaba contraindo o vírus do HIV ... (P.16).

O processo de confirmação diagnóstica do HIV foi um caminho solitário, marcado por sentimentos de negação, sofrimento e isolamento que trouxe para a vida dessas pessoas demandas terapêuticas e sociais complexas. Foi uma trajetória marcada por fatores determinantes para a procura pelo serviço de saúde e confirmação do diagnóstico. Entre esses fatores, estiveram a presença de sintomas, o conhecimento do diagnóstico do parceiro e situações ocasionais de acesso ao serviço de saúde para realização de exames como exames de rotina e doação de sangue. 
[...] surgiu no meu pênis uma ferida! Até então eu pensei que era uma ferida normal! Eu não cuidei! Eu vi que estava custando a sarar! [...] eu fui fazer um exame para saber o que que era na verdade! [...]deu que era sífilis e HIV! (P.15).

[...] eu ia fazer se eu não me engano 18 anos! O meu ex namorado ele estava doente! A gente teve uma briga e teve um término! [...] quando a gente voltou a mãe dele resolveu me contar que ele tinha [HIV]! [...] foi quando eu fiz o exame e deu positivo para o HIV! [...] estava com ele há dois anos! (P.6).

Mediante a confirmação diagnóstica, os participantes descreveram que passaram a vivenciar a busca por explicações para a ocorrência do HIV. Para a maioria, a forma de transmissão foi a relação sexual desprotegida, com parceiros eventuais; parceria sabidamente positiva e com parceiros fixos (anteriores e atuais).

A justificativa para a exposição sexual desprotegida foi, principalmente, a confiança no parceiro por vivenciar um relacionamento estável e o prazer do sexo sem preservativo. Entre os participantes que informaram a transmissão por meio da relação sexual, oito vivenciam atualmente relacionamentos soroconcordantes e dois relacionamentos sorodiscordantes.

[...] confiava muito nas pessoas! Mas também não era uma coisa que eu confiava e transava sem camisinha! Então eu sabia que era possível contrair em uma vez só! Mas aquele negócio: "Ah, é bonitinho, tem uma pele bonita! " [...]eu sabia do risco, mas fazia de conta que não sabia. Eu tinha esses pensamentos antes! Hoje eu não tenho mais! (P.14).

Para alguns a infeção não foi ocasionada por relação sexual. Eles apontaram a suspeita da ocorrência da transmissão sanguínea por meio de compartilhamento de instrumentais (alicates, tatuagens), acidente com material biológico (perfuração com agulha), cirurgia e transfusão de sangue.

[...] eu tive um tumor [...] recebi transfusão de sangue. Já mexi com muito sangue também em acidente, trabalhava em caminhão e via muito acidente! [...] peguei isso (HIV) não sei como! [...] não sei como aconteceu! Ela também não sabe! (P.10) Então se aconteceu, Deus que quis assim para provar alguma coisa para nós dois. [...] desde que eu estou com ela, eu não fiquei com mais ninguém depois que nós estamos juntos e antes sempre era de camisinha, então assim, eu fico sem entender (P.9).

Alguns relataram o medo da morte imediata ou de se tornarem dependentes do cuidado dos familiares, após receberam a confirmação diagnóstica. Além do medo foram descritos sentimentos relacionados a culpa; sofrimento; incertezas e inseguranças sobre sua própria saúde e futuro; tristeza; negação/não-aceitação; desespero; desânimo; privação e sentimento de inutilidade.

[...] tem hora que não acredito que eu tenho isso, que é mentira! [...] sentimento de desespero até hoje! Não passa não! Eu acho difícil conviver [com o diagnóstico] eu não gosto nem de ficar conversando muito sobre $o$ HIV. [...] parece que eu não me aceito, que eu tenho nojo de mim, do meu corpo! Parece que eu estou podre por dentro! (P.3).

[...] um peso na consciência, uma culpa! Sentimento de que a qualquer hora pode acontecer alguma coisa com você, relacionado a saúde! (P.19).

Outro aspecto identificado foi o isolamento social relacionado ao medo da rejeição/ discriminação do parceiro (a), familiares e amigos frente ao diagnóstico de HIV. Viver o "mundinho escondido", foi descrito como modo de afastar o preconceito e o julgamento da sociedade. 
[...] até hoje eu tenho dificuldade de me relacionar com pessoas! [...] nem ir à igreja eu não vou mais! [...] porque tem pessoas boas, mas tem pessoas também maldosas, comentários sabe?! [...] festas não gosto de ir! Eu tenho ainda um pouco de dificuldade de ir e mostrar que estou alegre e feliz. Eu tenho meu mundinho assim mais escondido! (P.1).

A falta de informações sobre as formas de transmissão do HIV prejudicou o convívio sócioafetivo com a família e parceria. O medo de expor a rede de apoio ao risco de infecção, contribuiu para privação de atividades rotineiras.

Ela ficou depressiva e passou a me esnobar, não me querer, sabe?! [...] ela não aceita muitas vezes eu pôr a mão nela "Não, não, você não está com a mão cortada?!" E isso muitas vezes esfria né, não tem jeito. [...] então mudou bastante, mas devagarzinho vai superando (P.4).

[...] eu tinha medo até do beijo. Do beijo de tudo assim, de pegar na mão, de tudo assim, eu tinha medo de tudo, de piorar assim sabe?! Porque a gente não tinha informação (P.10).

A percepção de que o HIV é o fim, também gerou situações de vulnerabilidade, e revelou a necessidade de apoio emocional e suporte psiquiátrico frente a presença de sintomas depressivos, até mesmo a tentativa de suicídio. Os relatos de depressão foram evidenciados, especialmente frente ao sentimento de desconforto, medo, culpa e vergonha com a possibilidade de ter transmitido e ou transmitir aos familiares e parceria, especialmente entre casais sorodiscordantes.

[...] eu estou com preconceito comigo mesma! Porque eu não aceito, não aceito! Eu entrei em depressão! Faço tratamento psiquiátrico tudo por causa dessa doença. É muito difícil para mim até hoje! Já tem três anos que eu descobri e mesmo assim ainda não passou! [...] eu não deixo ninguém chegar perto de mim, com medo de passar para eles (P.3).

Apenas três entrevistados mencionaram aceitação, tranquilidade e confiança em um desfecho positivo no momento da confirmação do diagnóstico. Essas pessoas vivenciam relacionamentos soroconcordantes e descreveram aspectos como ter uma personalidade tranquila, observar pessoas que convivem com a enfermidade há muito tempo e a necessidade de enfrentar positivamente o tratamento.

[...] quando eu tive relação sexual desprotegida, na hora eu não pensei, mas era um risco que eu estava correndo [...] então tipo, na hora é difícil, não é fácil para ninguém, mas não me levou ao desespero! [...] me levou a possibilidade "Poxa, agora com essa doença eu tenho que tratar, não tenho outra alternativa" (P.16).

Os participantes descreveram a necessidade de readaptação as atividades da vida diária. Essas readaptações foram relacionadas às mudanças na rotina de trabalho (limitações relacionadas a fraqueza para o desempenho de atividades ocupacionais), adoção de hábitos alimentares saudáveis e a necessidade do seguimento e acompanhamento terapêutico no serviço de saúde. Essas mudanças foram necessárias para manutenção de "uma vida normal". Eles destacaram também a importância da adesão a terapêutica medicamentosa para a recuperação em médio e longo prazo.

[...] depois que eu descobri a questão do HIV eu procuro me precaver ao máximo possível para evitar que eu tenho complicações. [...] eu procuro me policiar na alimentação, no sono, até nas questões do dia a dia mesmo! Eu procuro me policiar para ser uma pessoa melhor! [...] ter uma qualidade de vida melhor do que eu tinha antes! [...] eu não traço metas para daqui 30 anos igual eu traçava antes! Agora é mais a curto e médio prazo! Apesar de saber que o meu organismo ele é um tanto quanto frágil! Talvez até uns 60 anos eu consigo chegar (P.16) 
Considerando o contexto das mudanças e readaptações, alguns participantes relataram ter medo dos desafios que poderão vivenciar nos relacionamentos futuros, o preconceito e estigma que poderão sofrer pelo conhecimento do seu diagnóstico por futuras parcerias. A percepção de preconceito que poderão vivenciar nos novos relacionamentos causa insegurança, medo e tristeza pela possibilidade de rejeição do outro e o receio em se expor ao vírus. As atitudes que tinham antes do diagnóstico eram de afastamento de pessoas que viviam com HIV, portanto acreditam que o outro também terá esse posicionamento.

\title{
[...] antes de eu ser soropositivo se eu fosse ficar com alguém por mais interessante que a pessoa fosse, se a pessoa me falasse (que tinha HIV) eu não ia querer ficar com ela. Não por preconceito e sim por medo de acontecer um acidente e acidentalmente eu contrair o vírus sendo que eu poderia ter ficado longe. Então eu acho que a pessoa poderia pensar igual a mim (P.14).
}

Em termos do atendimento inicial no serviço de saúde, os participantes mencionaram o despreparo dos profissionais para diagnosticar, comunicar o diagnóstico e referenciar as pessoas na rede de atenção à saúde. Esse aspecto contribuiu para sentimentos de angústia, desânimo e medo da morte. Para eles a falta de informações, de apoio profissional, o uso de terminologias técnicas pelos profissionais, falta de acolhimento/empatia acarretaram a demora pelo diagnóstico e início do tratamento e também influenciaram na autoaceitação inicial da enfermidade.

\begin{abstract}
[...] a Dra não teve sabedoria para falar comigo, ela falou que logo eu teria infecções, que a minha pele eu ia ter um problema de pele, que se eu pegasse até uma chuva eu ia dar pneumonia. Ela me deu um diagnóstico de morte antes da hora, um diagnóstico de morte e eu pensava assim: "Meu Deus!". [...] talvez se a Dra (atenção básica) tivesse o preparo que ele (infectologista) tem, eu não tivesse saído de lá tão triste (P.12).
\end{abstract}

\section{Discussão}

O estudo retrata a complexa realidade social vivenciada por pessoas no enfrentamento do HIV em contexto de relacionamentos estáveis. Essas pessoas vivenciam dilemas pessoais, sociais e do modelo de atenção à saúde que demandam uma reflexão crítica para os avanços necessários para a efetiva promoção da saúde e melhoria de suas qualidades de vida. A segurança ocasionada pela vivência de um relacionamento estável interfere na percepção de risco, pela crença de fidelidade e monogamia que esses relacionamentos estão vinculados e gerou o sentimento de confiança também retardou a busca pelo serviço de saúde (Maksud, 2012).

O processo de confirmação diagnóstica geralmente é apontado como solitário e com repercussões sociais e emocionais que impactaram no enfrentamento de planos futuros desses relacionamentos estáveis. Em geral, envolve o medo da morte, a percepção de enfrentamento do estigma social, conflitos nos relacionamentos sexuais e conjugais e o medo do preconceito e julgamento moral(Castellani \& Moretto, 2016; Maksud, 2012; Teixeira et al., 2006).

A infecção ainda é interpretada como uma doença associada a estigma, promiscuidade e julgamento moral de responsabilização da pessoa infectada como merecedora desta situação. Neste contexto, a estratégia empregada por alguns é a opção de "viver o mundo escondido", como forma de refúgio e de proteção, frente ao preconceito, exposição e julgamento da sociedade. Alguns estudos descrevem que esse processo de reconstrução identitária, na maioria das vezes envolve percepções negativas e estigmatizantes que contribuem para o enfrentamento negativo e solitário da enfermidade que pode levar essas pessoas à transtornos emocionais que requerem o acompanhamento adequado em termos de sua saúde mental(Gomes et al., 2011; Weiss \& Ramakrishna, 2006). 
Aspectos relacionados ao estigma foram descritos tanto no contexto de vida social dessas pessoas, mas também em termos dos serviços de saúde através da percepção de préjulgamento dos profissionais de saúde, na fase diagnóstica. Esses aspectos contribuíram para o afastamento do serviço de saúde trazendo prejuízos para o tratamento imediato dessas pessoas, bem como as orientações necessárias para adoção de práticas sexuais preventivas.

O convívio social prévio com pessoas soropositivas e o suporte dos familiares fortaleceu a percepção de que é possível conviver com HIV. Essa tem sido uma estratégia recomendada aos serviços de saúde para trabalhar aspectos que demandam autocuidado, benefícios emocional, comportamental e físico, e que tem efeitos satisfatórios na autoestima e minimizam a autopercepção dos fatores estigmatizantes relacionados à infecção. Em estudo realizado com mulheres soropositivas, foi destacado pelo autor o impacto positivo das estratégias em grupo, a percepção de superação do outro, motiva o indivíduo a buscar estratégias para o seu enfrentamento individual(Lennon-Dearing, 2008).

Entre os desafios enfrentados, o medo da transmissão entre os casais sorodiscordantes e o receio em prejudicar ainda mais o parceiro (entre casais soroconcordantes) foi descrito como prejudicial e dificultado para o processo de autoaceitação e aceitação do diagnóstico. Em alguns casos, os sentimentos de receio em transmitir o vírus ao parceiro soronegativo, medo do julgamento, vergonha, culpa, ódio de si mesmo e angústia pela percepção do parceiro levaram ao rompimento da relação ou à abstinência sexual (Eaton et al., 2009)

A inclusão da parceria estável soronegativo ainda é um desafio na prática assistencial que está centrada no modelo biomédico, e enfatiza o paciente infectado e negligência a parceria. Em alguns países a busca pela parceria de pacientes com HIV já se tornou rotina nos serviços de saúde. Após o diagnóstico positivo, o parceiro é contatado para também ser testado e então são tomadas as providências de acordo com a sua sorologia. Essa prática foi descrita em alguns estudos como satisfatória(Allen et al., 2007; Coates et al., 2008).

\section{Conclusões}

Por meio desta interpretação descritiva, compreendeu-se que vivência do HIV no contexto de parcerias estáveis implica no enfrentamento de situações sociais e afetivas complexas que demandam do serviço de saúde a incorporação e o aprimoramento de estratégias que favoreçam o engajamento da pessoa soropositiva, mas também a parceria estável.

Graças aos avanços terapêuticos é possível conviver com o HIV e ter o sucesso terapêutico para manutenção das atividades de vida diária e os relacionamentos socioafetivos. A prática do sexo seguro e do acolhimento e aconselhamento de casais que convivem com o HIV são desafios permanentes, que se distinguem de indivíduo para indivíduo. Esses desafios requerem uma atenção específica e efetiva dos profissionais de saúde, principalmente, no complexo processo de cuidar de casais expostos ao HIV, no sentido de evitar danos e minimizar a vulnerabilidade e suscetibilidade à infecção pelo vírus entre esses casais além de manter uma qualidade de vida sexual satisfatória.

Para isso, é fundamental o apoio e aconselhamento dos profissionais como mediadores de possíveis conflitos que possam advir frente à necessidade de revelação do diagnóstico para a parceria. A inserção da parceria estável no plano terapêutico deve ser parte de um protocolo assistencial do HIV. Nessa perspectiva a intervenção com o paciente soropositivo deverá reforçar a importância de cuidar de si e a responsabilidade por cuidar do outro. 
No contexto da vivência do HIV entre casais estáveis, todos os esforços de prevenção devem ser demandados considerando o casal como unidade de mudança. A abordagem individualizada sem considerar a complexidade e díade tende a ser falha e desintegrada, pois não é capaz de abranger a totalidade do casal. A oferta de informações esclarecedoras, acessíveis e que despertem a compreensão e interesse do indivíduo em adotá-las são necessárias para a manutenção das atividades sociais e sexuais do casal e do vínculo social.

\section{Agradecimentos}

À Fundação de Amparo à Pesquisa do Estado de Goiás - FAPEG, por subsidiar este estudo.

\section{Referências}

Allen, S., Karita, E., Chomba, E., Roth, D. L., Telfair, J., Zulu, I., Clark, L., Kancheya, N., Conkling, M., Stephenson, R., Bekan, B., Kimbrell, K., Dunham, S., Henderson, F., Sinkala, M., Carael, M., \& Haworth, A. (2007). Promotion of couples' voluntary counselling and testing for HIV through influential networks in two African capital cities. BMC Public Health, 7, 349. https://doi.org/10.1186/1471-2458-7-349

Braun, V., \& Clarke, V. (2014). What can "thematic analysis" offer health and wellbeing researchers? International journal of qualitative studies on health and well-being, 9.

Castellani, M. M. X., \& Moretto, M. L. T. (2016). A experiência da revelação diagnóstica de HIV: o discurso dos profissionais de saúde e a escuta do psicanalista. Revista da SBPH, 19, 24-43. http://pepsic.bvsalud.org/scielo.php?script=sci_arttext\&pid=S1516$08582016000200003 \&$ nrm $=$ iso

Coates, T. J., Richter, L., \& Caceres, C. (2008). Behavioural strategies to reduce HIV transmission: how to make them work better. Lancet, 372(9639), 669-684. https://doi.org/10.1016/s01406736(08)60886-7

Eaton, L. A., West, T. V., Kenny, D. A., \& Kalichman, S. C. (2009). HIV transmission risk among HIV seroconcordant and serodiscordant couples: dyadic processes of partner selection. AIDS Behav, 13(2), 185-195. https://doi.org/10.1007/s10461-008-9480-3

Gomes, A. M. T., Silva, É. M. P., \& Oliveira, D. C. d. (2011). Social representations of AIDS and their quotidian interfaces for people living with HIV. Revista Latino-Americana de Enfermagem, 19, 485-492. http://www.scielo.br/scielo.php?script=sci_arttext\&pid=S0104$11692011000300006 \&$ nrm=iso

Granich, R., Williams, B., Montaner, J., \& Zuniga, J. M. (2017). 90-90-90 and ending AIDS: necessary and feasible. The lancet, 390(10092), 341-343.

Guerriero, I. C. Z. (2016). A resolução 510/16: diretrizes éticas para pesquisas em Ciências Humanas e Sociais. Cadernos Brasileiros de Terapia Ocupacional, 24(3).

Lennon-Dearing, R. (2008). The benefits of women-only HIV support groups. Journal of HIV/AIDS \& Social Services, 7(1), 27-45.

Maksud, I. (2009). O discurso da prevenção da Aids frente às lógicas sexuais de casais sorodiscordantes: sobre normas e práticas. Physis: Revista de Saúde Coletiva, 19, 349-369. http://www.scielo.br/scielo.php?script=sci_arttext\&pid=S0103-73312009000200006\&nrm=iso

Maksud, I. (2012). Silêncios e segredos: aspectos (não falados) da conjugalidade face à sorodiscordância para o HIV/AIDS. Cadernos de Saúde Pública, 28, 1196-1204. http://www.scielo.br/scielo.php?script=sci_arttext\&pid=S0102-311X2012000600018\&nrm=iso

Malterud, K., Siersma, V. D., \& Guassora, A. D. (2016). Sample size in qualitative interview studies: guided by information power. Qualitative health research, 26(13), 1753-1760. 
Mogobe, K. D., Shaibu, S., Matshediso, E., Sabone, M., Ntsayagae, E., Nicholas, P. K., Portillo, C. J., Corless, I. B., Rose, C. D., Johnson, M. O., Webel, A., Cuca, Y., Rivero-Méndez, M., Solís Báez, S. S., Nokes, K., Reyes, D., Kemppainen, J., Reid, P., Sanzero Eller, L., Lindgren, T., Holzemer, W. L., \& Wantland, D. (2016). Language and Culture in Health Literacy for People Living with HIV: Perspectives of Health Care Providers and Professional Care Team Members. AIDS Res Treat, 2016, 5015707. https://doi.org/10.1155/2016/5015707

Paiva, V., Calazans, G., Venturi, G., \& Dias, R. (2008). Idade e uso de preservativo na iniciação sexual de adolescentes brasileiros. Revista de Saúde Pública, 42, 45-53.

Teixeira, A. M. F. B., Knauth, D. R., Fachel, J. M. G., \& Leal, A. F. (2006). Adolescentes e uso de preservativos: as escolhas dos jovens de três capitais brasileiras na iniciação e na última relação sexual. Cadernos de Saúde Pública, 22, 1385-1396.

Thorne, S. (2016). Interpretive description: Qualitative research for applied practice. Routledge.

Weiss, M. G., \& Ramakrishna, J. (2006). Stigma interventions and research for international health. Lancet, 367(9509), 536-538. https://doi.org/10.1016/s0140-6736(06)68189-0 